\title{
TIN MINING AND SILICOSIS IN CORNWALL*
}

\author{
BY
}

L. W. HALE

\section{Camborne and Redruth Miners and General Hospital}

In recent years pneumoconiosis among miners has increasingly attracted the attention of students of respiratory disease, and the urgent problem which it now presents in the South Wales coalfields, together with the importance of the industry involved, has produced a considerable literature dealing with pneumoconiosis and the environmental considerations relative to it.

It is thought that the practice of tin mining may be less well known to workers in this field, and it is the purpose of this communication to outline the processes involved, especially as they bear upon the production of silicosis, and to review briefly the features of this "classical" silicosis.

\section{NATURAL History}

In the simplest terms Cornwall may be considered geologically to consist of a stratum of clay slate (called killas), overlying the granite, the former being a sedimentary and the latter an igneous formation. The depth of the killas is variable, while the granite continues to great depth, becoming increasingly hot and finally plastic, in which state it is known as the magma, the precursor form of all igneous rocks.

As a result of major ground-movements which occurred in the early history of the earth, the granite has in places bulged upward and intruded the killas layer, fracturing and altering the slate and producing fissures which are commonly continuous with fissures present in the underlying granite as a result of the bending force to which it was subjected when it bulged upward.

Mineral matter originating in the magma and held in solution in vapours (mainly water vapour under high temperature and pressure) escaped from below into the fissures, and the minerals in solution were deposited at different depths in the fissure according to their individual properties of continuing in solution as temperature and pressure decreased toward the surface of the earth. The process may be likened to that of separation by fractional sublimation in chemistry.

These fissures, containing minerals and altered rock, constitute the metalliferous lodes; the more important metals found in them, in the order of their deposition from below upward, are tin, copper, zinc, and lead. Among other minerals which occur are arsenic, antimony, silver, gold, tungsten, and uranium, none of which, however, is present in profitable quantity save wolfram (tungsten

*Based on a paper read before the Medical Society at Sully Hospital, Cardiff, on January 11, 1946. 
oxide) in a few districts. The tin-bearing lode consists of cassiterite, a rock darker than Cornish granite, and containing stannic oxide, quartz, mica, felspar, and other constituents.

Ground-movement in Cornwall at different periods of time has produced two main series of fissures, the first running mainly NE-SW and generally mineralized, and the second running NW-SE, non-mineralized, younger, and often "faulting " (displacing) the first.

For the reasons stated above the metalliferous lode lies roughly in the vertical plane, unlike the coal-seam, which tends to be in the horizontal, and just as the latter may "dip " in an upward or downward direction, the lode may "lean" at an angle from the vertical; indeed, the extraction of the lode may be likened to the lifting out of a card from between two books on a shelf.

The lode as seen at the working-face (or development drive) appears as a dark vertical streak in the granite, its width in the mines at present worked being seldom greater than $3 \mathrm{ft}$. ; veins less than a foot wide are profitable if the mineral content is high.

In the areas where the killas has been intruded by granite, elevations of the earth's surface result, and centuries of attrition by weathering effect a decapitation of these elevations in like manner as the top is cut off a boiled egg. The material removed by weathering tends to be washed down that slope which is to leeward of the prevailing wind, and consists of debris of slate, granite, and the uppermost edge of any lode which has been exposed and broken up. This material, drifted to the nearest valley, constitutes an alluvial ore-deposit, and it was from "tinstone" found in such deposits and crushed in a crude form of stone pestle and mortar and subsequently smelted in a stone fireplace, that man first obtained metallic tin.

The denuded top of the elevation at this stage would show a centre of granite, which may be likened to the yolk of the cut egg, surrounded by a zone of altered slate (called the metamorphic aureole), which is also mineralized. Beyond this zone the slate is unaltered.

It will be seen (Fig. 1) that where the granite has been uncovered on the summit of an elevation, and has itself been subjected to weathering and erosion, the uppermost part of the fissures containing metal will have been washed away, and the deeper part only (containing copper and tin or tin alone) will be found ; while in the metamorphic aureole the fissure will tend to persist in its entirety, and here zinc and lead are to be expected, with copper and tin at greater depths.

The average width of the aureole in Cornwall is 5 to 7 miles.

\section{Lode Mining}

The earliest tinners, having exhausted the supply of tinstone in an alluvial deposit, would speedily discover the presence of a quantity of the same material on the slope down which it had been washed, and following this uphill would come to the spot where the lode was exposed on the surface. 
The most primitive form of lode mining consisted of excavating the ore from these exposed lodes by a sort of trenching to such a depth as was practicable, the ore being hauled to surface in baskets. This method had the great disadvantage that, as the lode seldom continues for any great depth to be in the true

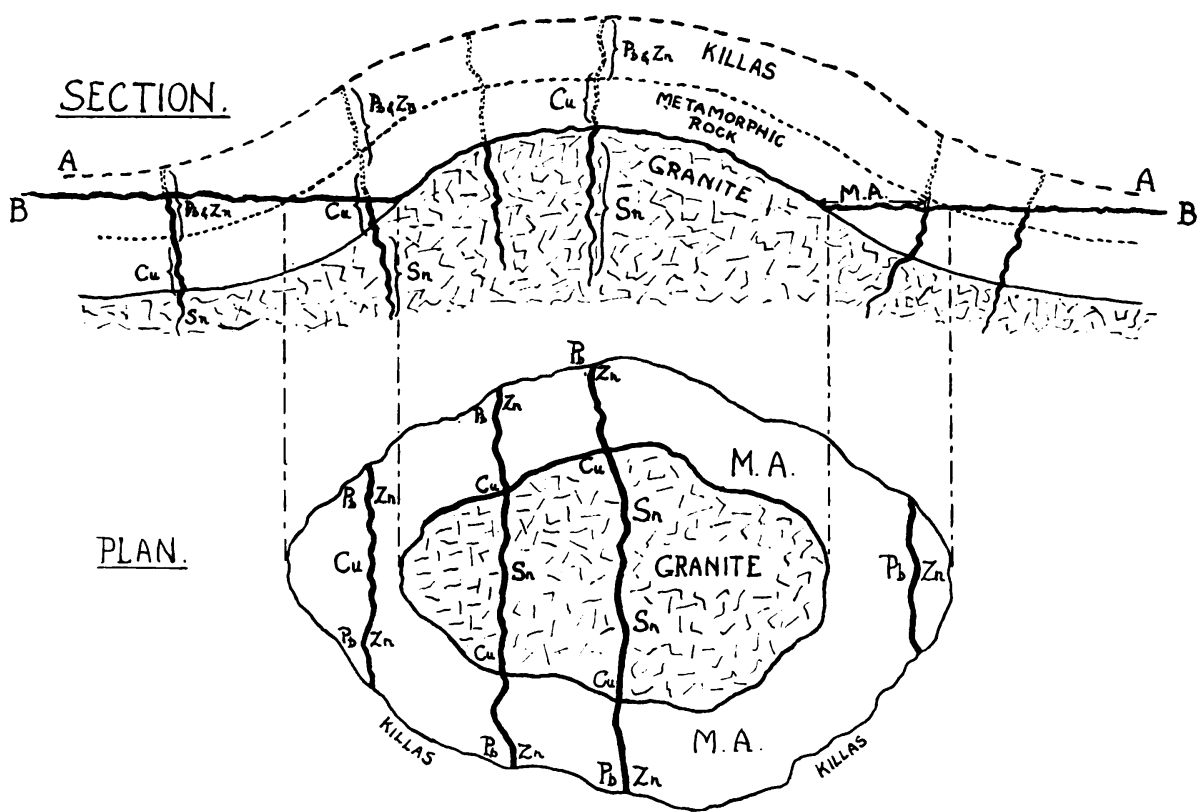

FIG. 1.-Diagram of metalliferous fissures in granite and metamorphic aureole (M.A.). AA, Original land surface ; BB, Present land surface (the granite remains as an outcrop). Lodes removed by weathering are indicated by dotted lines.

vertical plane, the open working resulting from its excavation commonly descended in an oblique plane, often dipping back in an opposite direction as it extended downward and then resuming its previous course (Fig. 2). The zig-zag line which a basket thus took on its way from the bottom to the surface made haulage extremely difficult, and often necessitated the abandoning of the work.

(a) Layout of Shaft, Levels, etc.

To avoid the above difficulty the present-day miner, having discovered his lode, sinks the shaft at a convenient distance to one side of its course. This permits of its being sunk in good granite rather than the less durable lode rock-a considerable advantage, as the shaft is the most permanent and important part of the working.

From the shaft, tunnels known as "cross-cuts" are run out horizontally to strike the lode at right angles, one cross-cut every $100 \mathrm{ft}$. down from surface. At the point where these meet the lode further horizontal tunnels are driven at right angles to the cross-cut, following the lode in both directions. These latter are called development drives, or "levels." 


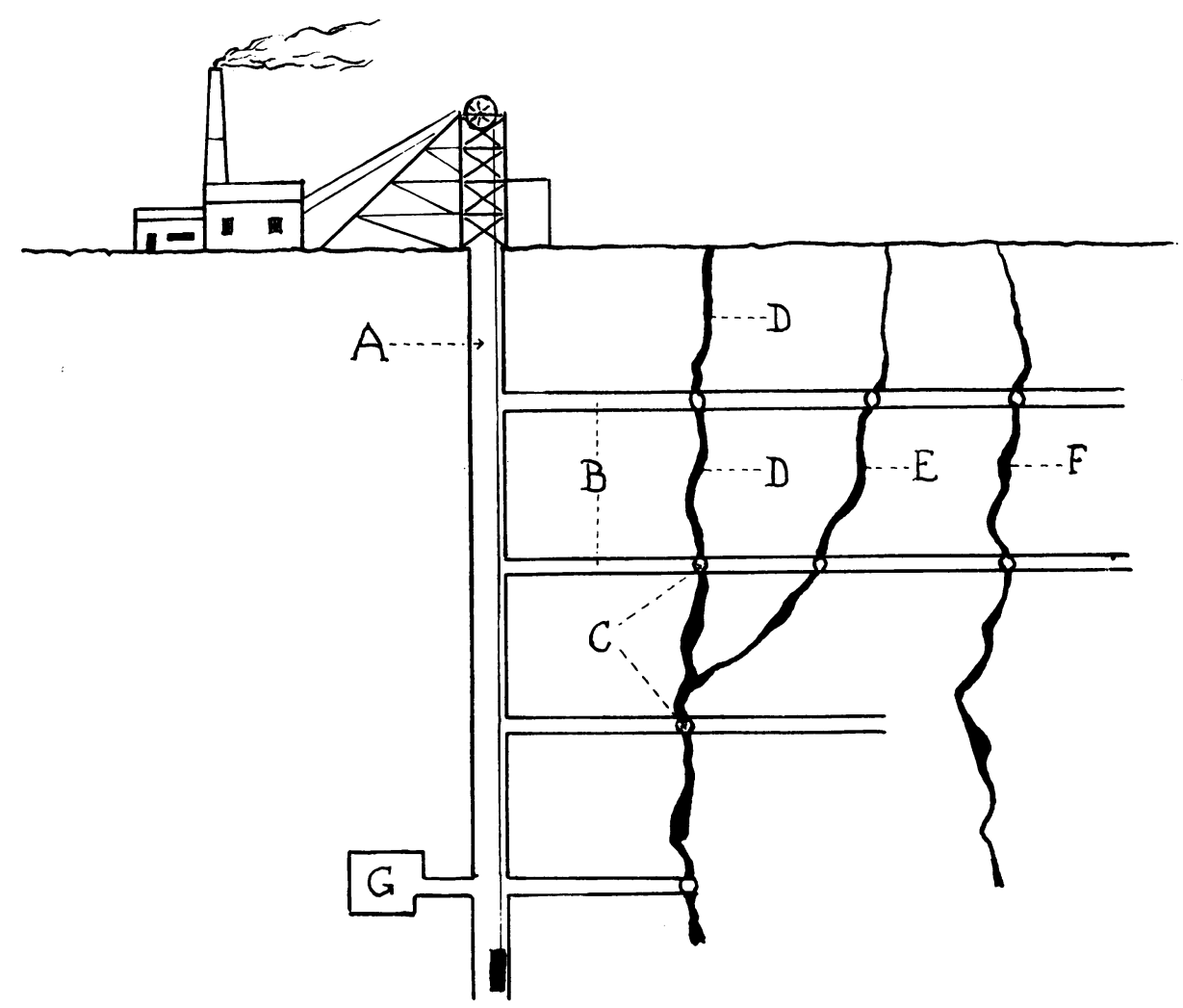

FIG. 2.-Transverse section of main and subsidiary lodes. A, Shaft ; B, Crosscuts ; C, Opening of level into crosscut; $D$, Main lode; $E$ and $F$, Subsidiary lodes; G, Pumps.

The process of breaking out rock to form cross-cuts or levels is known as "driving," and is done by the most skilled miners. The development driver works with one man as his mate, and aims to break out a portion of rock about $7 \mathrm{ft}$. high by $6 \mathrm{ft}$. wide (this being the usual sectional area of a level) by $6 \mathrm{ft}$. in a forward direction, per working shift. This is done by drilling in the rock face a number of shot-holes at calculated angles to the face, and up to $6 \mathrm{ft}$. in length. These holes, or groups of holes, are known as the "stab," "cuts," "easers," "knee-holes," "shoulder holes," "back-holes," and "lifters" (Fig. 3). When drilled and cleaned out, the groups of shot-holes are charged with the appropriate quantity of gelignite. The length of fuse allotted to each group is varied so that the charges shall not all explode simultaneously, but in a pre-arranged sequence at intervals of about $3 \mathrm{sec}$. The stab-hole charge explodes first and shatters the centre of the face, the four cut-holes next break out a cone of rock having its base on the face, and so on, the "lifters" exploding last and throwing the whole broken mass forward into the level ready for tramming away. 
Further reference to the drills will be made below.

At intervals of about $300 \mathrm{ft}$. along the course of each level, vertical shafts are excavated, called "raises" when they are being excavated upward, and "winzes" if downward, and these connect the level from which they proceed with the next level above or below. When they cease to be blind shafts (that is,

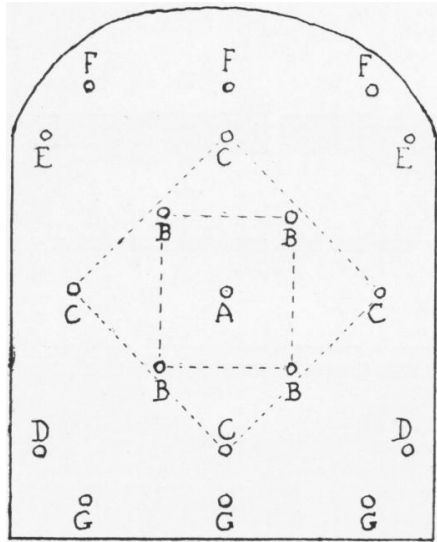

Transverse Section

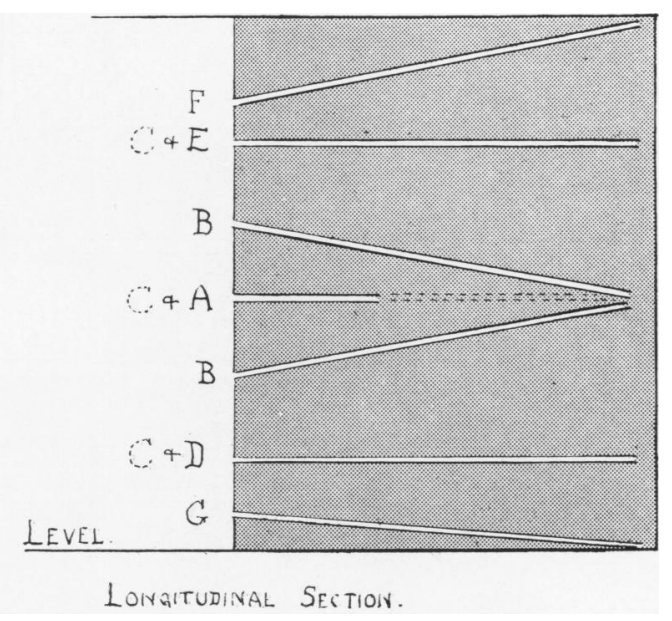

FIG. 3.-Diagram of commonly used pattern of drilling to secure a $6-\mathrm{ft}$. advance in the development drive. A, Stab-hole ; B, Cut-holes ; C, Easers ; D, Knee-holes ; E, Shoulderholes; F, Back-holes; G, Lifters. (The four cut-holes are aligned to converge, and the back-holes and lifters are sloped towards the roof and floor respectively.)

connect with a level above and below) they are called connections. When a number of such connections have been made the section of lode involved is thereby divided into a number of "blocks," each bounded by a level above and below and a connection at each end (Fig. 4). The ore is then removed by a process known as "stoping."

\section{(b) Stoping}

Stoping consists of the breaking out of the ore from the "block" in a series of sections roughly $6 \mathrm{ft}$. by $4 \mathrm{ft}$. viewed laterally, and thick enough to take out the whole width of the metalliferous lode plus enough of the adjacent countryrock to give a cavity about $40 \mathrm{in}$. from side to side, this being the narrowest width in which the miner can work conveniently.

Stoping is also performed by a skilled miner working with a mate, but the shot holes are drilled in whatever pattern seems expedient, and the charges are fired simultaneously or in two groups only.

The stoping operation is commenced at the lower corner of the block, and shortly afterward at the upper corner also.

The miner working the lower corner (overhand stoping) starts his work from the level which runs below the block. He first brings down the roof of this level 
for a length (or " bench ") of $50 \mathrm{ft}$. horizontally from where it joins the connection and to a vertical height of $5 \mathrm{ft}$; the ore and rock so broken out falls down on the floor of the level. Standing upon this pile of broken rock, he again brings down the roof above him for a " bench" of similar length and height. The floor

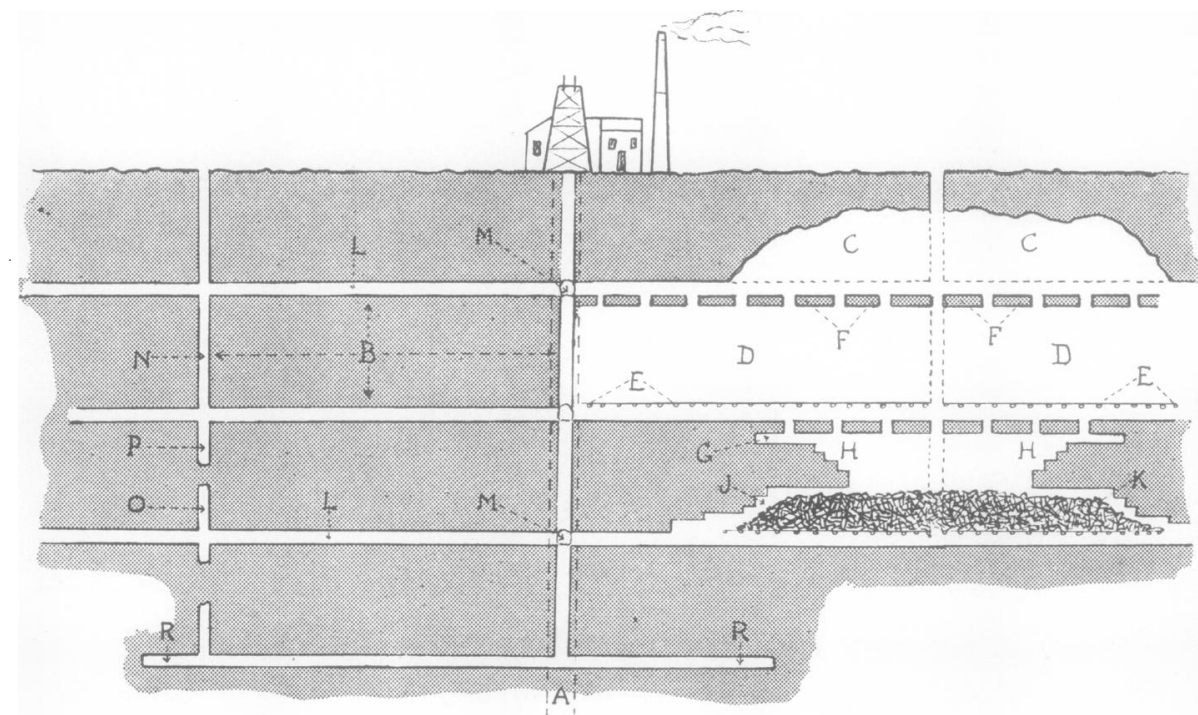

Fig. 4.--Diagram of longitudinal section on main lode. A, Line of shaft (dotted); B, Block ; C, Stope-cavity in block of poor ore, abandoned; D, Stope-cavity completely worked out ; E, Stulls and lagging; F, Pillars; G, Stope drive ; H, Underhand stoping ; J, Overhand stoping; K, Broken ore pile ; L, Level ; M, Crosscut opening into level; N, Connection: O, Raise ; P, Winze; R, Development drive. (Where connection has ceased to exist it is indicated by dotted lines.)

of the level is now obstructed by the pile of ore, and this is removed to clear the way. At the height of the original roof of the level (before the benches were broken down), or a little higher, a wooden platform is now put in, of lengths of pit-propping timber ("stulls") fixed transversely across the level, with planks ("lagging ") laid longitudinally upon them; the whole now forming a wooden roof to the level and having a type of trap-door (ore-chute) opening through it into the stope-cavity above, every $15 \mathrm{ft}$. of its length. The function of the lagging is to catch further ore broken down from above by the overhand-stoper and so keep the level clear for passage of trams, etc.

The miner now stands upon the lagging to work, and brings down the roof above him in sections about $6 \mathrm{ft} . \times 4 \mathrm{ft} . \times 40$ in. transversely, at the rate of about three sections per working-shift (Fig. 5). The broken ore falls down on the lagging and is allowed to accumulate there in the stope-cavity piled to just such a height that the miner, standing upon it, can conveniently reach the lode above him for drilling. Excess ore over this requirement is withdrawn from below via the ore-chutes and trammed away. 
Meanwhile the miner, working at the upper corner of the block (underhand stoping) stands on a platform rigged across the connection about $15 \mathrm{ft}$. below the floor of the upper level, and runs a tunnel (the stope-drive) $5 \mathrm{ft}$. high, parallel to the level and below it. This leaves $10 \mathrm{ft}$. of rock between the stope drive and

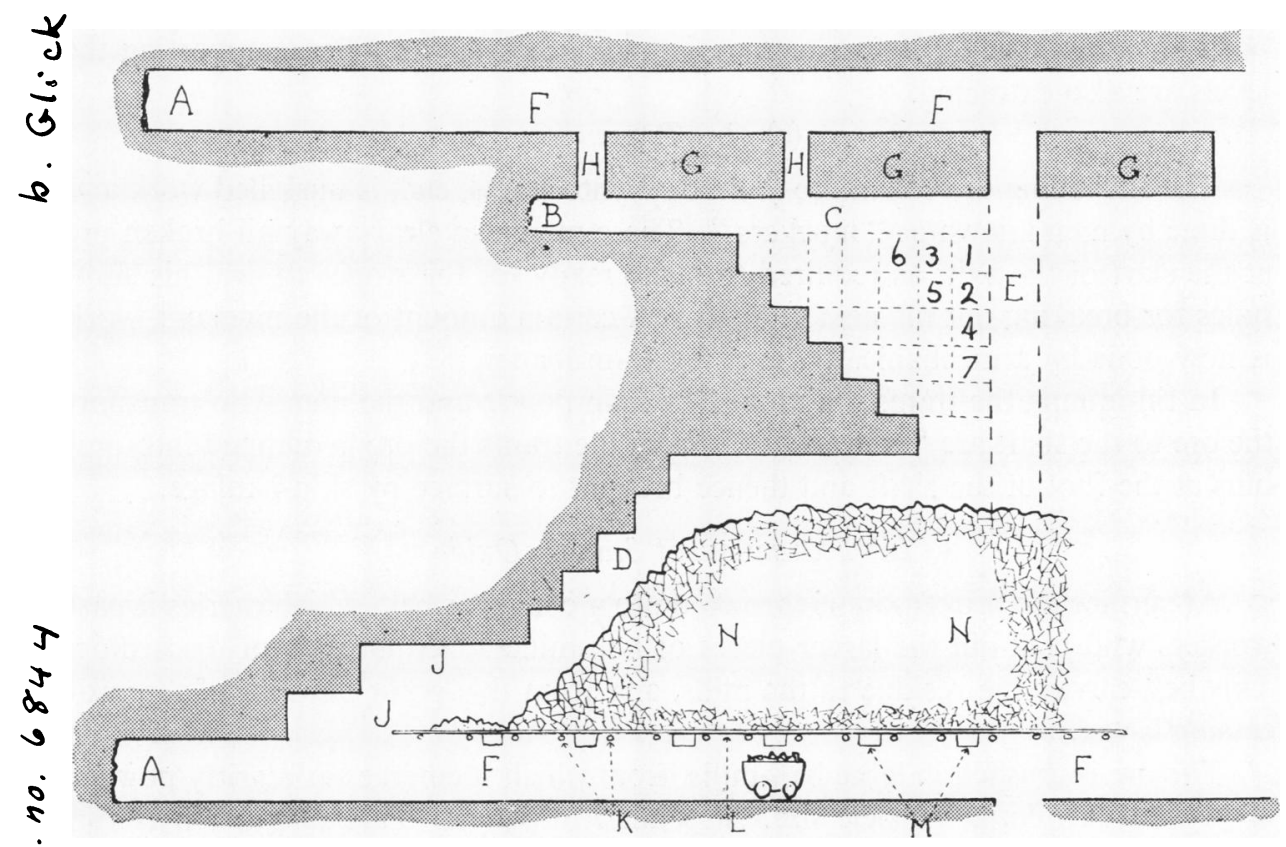

FIG. 5.-Detail of stoping. A, Development drive ; B, Stope drive ; C, Underhand stope ; $D$, Overhand stope ; E, Line of original connection ; F, Level ; G, Pillar ; H, Manway; JJ, Benches; K, Stulls ; L, Lagging; M, Ore chute ; N, Broken ore pile. (The figures $1,2,3$, etc., indicate order of breaking out sections by underhand stoper.)

the level, to support the floor of the latter. When the stope drive has run $20 \mathrm{ft}$. horizontally, a small upward tunnel about $3 \mathrm{ft}$. diameter (a "manway") is made to open into the floor of the level above. The section of rock (or " pillar") thus left to support the floor of the level is $20 \mathrm{ft}$. long $\times 10 \mathrm{ft}$. deep, and manway openings (usually covered by planks laid over them) occur about every $20 \mathrm{ft}$. along the floor of a level where stoping is, or has been, in progress.

When the first manway is open into the level the miner is able to enter the stope drive thereby, and the platform across the connection is removed so that the ore as it is broken out can be thrown down to join the pile broken by the overhand stoper.

The underhand stoper next goes to the end of the stope drive which joins the connection and breaks out sections of the block about $6 \mathrm{ft} . \times 4 \mathrm{ft}$. from the floor of the drive, in the order indicated (Fig. 5), giving the floor of the stope-cavity a staircase pattern, the broken ore from the preceding shift being thrown down the 
connection before drilling is started. The underhand stoper drills his shot holes in the ground at his feet.

It will be seen that when the stopers have completely worked out two adjacent blocks at the same level, the connection between them will no longer exist as such, and what remains is a cavity in the rock $100 \mathrm{ft}$. vertically $\times 600 \mathrm{ft}$. horizontally $\times 40$ in. transversely. Before a mine is finally closed, the pillars supporting the levels are also extracted.

\section{(c) Ore Transport}

The shovelling of broken ore (" muck") into trams, etc., is unskilled work and is done by men known as " muckers." These men also clear away all broken ore at the start of the shift as required to make ready for the stoper to drill his shotholes for breaking out his next sections. A certain amount of the muckers' work is now done by a mechanically operated tram-loader.

In tin-mining the trams are moved by man-power and the men who transport the ore to the shaft are "trammers." From the trams the ore is dumped into orebins at the foot of the shaft and thence brought to surface by skip-haulage.

\section{(d) Extraction of Stannic Oxide}

At surface the broken ore is thrown on to a conveyor belt, which carries it past workers who pick out the larger pieces of non-mineralized granite for discarding. This belt carries the residue to the mills, and from this point onward all the processing is wet.

The ore is crushed in large ball-mills, from which it emerges as a gritty powder of about 125 micron particle-size, suspended in water. This suspension is run consecutively through a series of conical settling-tanks, in the first of which the heaviest particles settle out, etc. These coarser sediments are remilled and again put through the tanks, the same sample being remilled possibly three or more times.

The material which emerges in suspension from the last tank is then run over large flat concentrating-tables which are set at a slightly oblique plane and kept constantly oscillating at an amplitude of about 1 in. and a rate of some 90 oscillations per minute. The effect of this process is that the heavier stannic oxide particles "climb" up the slope of the table (whose surface is fluted to assist it) with the wash of each oscillation, and leave the table at its higher edge, while the lighter quartz, etc., remains in suspension and is washed down the slope with the water, leaving the table at its lower edge. The heavier moiety is rewashed and again sedimented, while the lighter moiety is also processed again to limit wastage.

The product of the final sedimentation is moist, heavy, chocolate-coloured or black, and of amorphous appearance, and consists almost entirely of stannic oxide ; it is known as "black tin." In this form the mineral leaves the mine and is shipped to the smelter.

A ton of good quality ore contains $35 \mathrm{lb}$. of "black tin." The extraction 
process, scrupulous though it is, recovers only 70 per cent of this. (It is of interest that almost invariably there are lesser operators established in the valley below the mine, through which the mine effluent flows ; these "tin-streamers" reprocess the effluent by a method evolved from that of their forefathers, who extracted alluvial tin, and they are able to make a profit from the crumbs which fall from the rich man's table.)

The mine, then, recovers about $24.5 \mathrm{lb}$. black tin per ton of ore crushed. Of this, 75 per cent is metal, say $18.5 \mathrm{lb}$. metallic tin. With tin about $£ 300$ per ton, the metal brings about $2 \mathrm{~s}$. 9d. per lb., less smelting charges.

The larger Cornish tin mines to-day are milling 4,000 to 6,000 tons of ore per month.

\section{THE DRILLS}

Although there are various types of drill in use in the Cornish mines they are all variants of the same principle and are pneumatically operated. The essential parts of the drill are: the case; the piston (actuated by compressed air); the chuck, or socket into which fits the drilling-bit ; and the steel drilling-bit which actually cuts into the rock. This "steel," as it is called, consists of a shank which fits into the chuck, a shaft, and a head (or " bit "), which carries four chisel-edges arranged in a cruciform pattern. A water-channel runs through the length of the steel and has its outlet-hole at the centre of the cross formed by the cuttingedges (Fig 6).

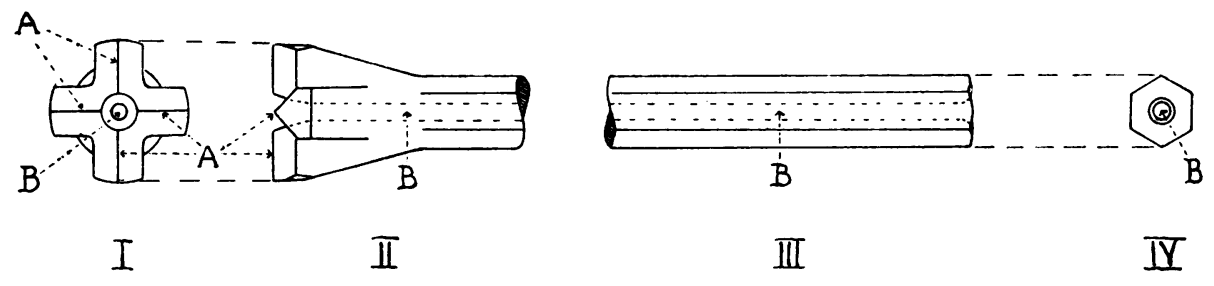

FIG. 6.-Diagram of drill-steel. I, Face of bit and cutting edges; II, Side view of bit;

III, Side view of shank; IV, End view of shank; A, Cutting edges; B, Water channel.

The rock is cut by percussion, the bit striking from 1,500 to 2,000 blows per minute, and being automatically rotated on its long axis about 120 times per minute. Water is fed to the machine by a flexible feed-pipe and passes through a hollow tube attached to the drill-case and projecting 1 in. or more down the channel in the steel, through which it feeds water to the rock-face being drilled. All patterns of drill used are fitted with this device and no dry drilling is done.

Development driving is done with a large fixed machine, overhand stoping with a machine which incorporates its own stand and is designed for drilling upward into the roof, and underhand stoping with a "jackhammer," which is essentially the familiar pneumatic road-drill fitted with a water-feed and the rock-cutting bit. Most types of machine have a device by which the compressed air can be turned direct through the channel in the steel if required, avoiding the piston, in order to clear the shot-hole if it becomes blocked with sludge. 


\section{ENVIRONMENTAL CONSIDERATIONS}

The country-rock in Cornwall is an acid granite, having a total silica content of 70 to 80 per cent, that of the metalliferous lode being slightly lower.

As the walls of the stope cavities, levels, etc., are of granite, comparatively little timbering for support is needed in a tin-mine; for the same reason, and because the lode occurs in the vertical plane, falls of roof are rare compared with their incidence in coal-mining.

Although tin-mines require a considerable water supply for the extraction processes, mines in this area tend to suffer from a surplus of water rather than a lack, and much pumping is required. In addition to naturally occurring water the wet-drilling and spraying devices in use combine to make the workings wet and muddy.

Naturally occurring gas is not found in the mines, and the tin-miner works by the light of a naked-flame acetylene lamp hooked into his hat. This is the sole source of light in the mine, for the levels, etc., are not electric lit.

The great amount of shot-firing done, however, produces a considerable quantity of carbon monoxide, together with irritant gases, mainly nitric oxide, and the quantity of the latter increases rapidly if gelignite is improperly detonated, for example, by incorrect ramming, tamping, or fusing of the charge. It is stated that nitric oxide, and sulphur dioxide, when inhaled have the property of temporarily paralysing bronchial cilia, and the release of these gases occurs synchronously with the highest concentration of harmful dust.

Many of the Cornish mines have been "hot," wet-bulb temperatures in the stopes ranging up to $90^{\circ} \mathrm{F}$., and the miner often works naked to the waist. The factor to which this is usually chiefly ascribed is the presence of iron pyrites in many of the lodes, undergoing oxidation when exposed to air and giving off heat. There are also often hot-water springs whose origin is deep in the igneous rock. Subsidiary causes are the shot-firing and drilling when they take place in an illventilated place. Heat, within bearable limits, is not wholly disadvantageous, for it results in upcast draughts which may be of value in ventilating the mine.

In the past, Cornish mines have reached depths of 3,000 ft., but those at present working are at about 1,500 to $2,000 \mathrm{ft}$.

\section{Dust Risk ann Prevention}

The dust risk in this industry is greatest in the operations of drilling, shotfiring, and the shovelling of ore into trams. Although dust may be found lying thick upon ledges in the walls of the stope cavities, the amount of this redispersed into the air is probably insignificant save at the time of shot-firing, after which operation the dust is exhausted by ventilation (see below). The disturbing of dust on the floor of levels, etc., by the feet of the men as they move about does not occur in tin mines (as it does in the coal-mine), owing to the constantly wet state of the floor. Dust-count figures are not at present available in Cornwall, though arrangements are now in hand for study of them. It may be stated that 
dust in such concentration as to be visually perceptible in suspension in the air is rarely seen in levels, nor even in stopes, provided that the preventive measures at present in use are being carefully applied. This is mentioned only to correct the impression that the miner to-day works in a "cloud" of dust ; it is recognized that dust, though invisible, is often present in harmful concentrations. When work has been done in an improper manner the atmosphere is comparable in appearance to that in a bathroom full of steam.

There are two factors beside dust which contribute occasionally to cause some haze in the mine atmosphere, namely, the presence of actual steam (if there are warm-water springs), and of droplets of atomized oil suspended in the air; the latter is derived from the exhaust of the drills, which are constantly lubricated when working by oil, which is fed to the mechanism in the compressed air that drives it. It is not yet known whether this oil is present in the atmosphere in any significant concentration, and whether it has any effect on ciliary epithelium, etc. ; it is probable that there is too little of it to have such effect, though it may have some incidental value in agglutinating dust particles.

The measures employed to combat dust are:

(a) "Natural ventilation," in which advantage is taken of the fact that the average temperature of the mine-workings exceeds that of the air at the surface. The provision of upcast and downcast shafts to and from surface will thus result in circulation of air through the mine, and by the installing of suitable doors the heavier cool air from the downcast can be conveniently distributed throughout the workings via the connections. If ventilation in any area is poor, the temperature there will rise as a result and increase the local upcast draught, thus tending to correct the fault. This is a primitive but often quite efficient method of ventilation, provided that the upcast and downcast shafts are reasonably "airtight" so that air-leakage cannot occur from one to the other.

(b) Wet-drilling, as described above. This, with improved ventilation, has been the greatest influence in dust control up to the present, and a demonstration of the dust cloud caused by using a drill with the water turned off provides an extremely impressive illustration of the great stride which was taken when this method was adopted.

(c) Mist-projectors (which spray atomized water, or a mist of oil and water) turned on during and after shot-firing. These have effect not only on the dust but also bring the nitric fumes into solution.

(d) Hand-operated water-sprays for directing water on the piles of broken ore before and during shovelling, and also for spraying down the walls of workingplaces at the start of every shift.

(e) A time-schedule whereby two shifts daily are worked and shot-firing is done only at the end of a shift. During shot-firing all the men leave the mine, with the exception of the drillers, who withdraw to a safe distance " upstream" in the air-current, and wait to count their shots as they explode (one of the most fertile sources of explosive accidents is the unsuspected persistence of a charge 
which has failed to explode). Having done this they also leave the mine, which is then blown through with compressed air for not less than two hours and remains empty for not less than three hours.

(f) Compressed-air rings (resembling a small lifebuoy of tubular steel with many perforations to "spray" the air). These are movable, the air being fed to them by a flexible pipe, and can be carried for extra ventilation to places where uncompleted rises or winzes have not yet connected to other levels, and in blind ends generally.

Difficulties in dust-prevention include:

(a) That while wet-drilling greatly reduces the dust dispersed, it does not wholly prevent it. The coarser particles are fairly efficiently wetted but those of two microns or less, which remain longest suspended in the air and by reason of their high ratio of surface to mass are most soluble in the lung, are stated to be more difficult to wet. It is known that surprisingly high dust-counts may be obtained from the air surrounding a water-fed drill-steel, although no dust cloud may be visible. The continued use of drills whose mechanism has become worn reduces the efficiency of the wetting process, so that unless servicing is regularly done a drill of good pattern may be found to cause dust. There is also a possibility in certain designs of drill that compressed air as well as water may enter the water-channel in the steel and form bubbles in the hole being drilled and so carry dry dust into the air ; a recently developed specially vented drill makes it impossible for this to occur. This difficulty of effectively wetting small particles also reduces the value of mist projectors and sprays.

(b) To be wholly satisfactory ventilation should thoroughly exhaust air-borne dust from all parts of the mine. The shape of a stope (two irregular triangular cavities set apex-to-apex) makes the occurrence of air-eddies almost inevitable, and in such places dust will remain suspended for long.

(c) Various types of respirator fitted with a dust-filter have been designed, but it has been found difficult to prevail on the miner to wear them. It must be admitted that an efficient type, in which a man may be comfortable while doing hard work, has yet to be evolved.

(d) Failure of the miner to apply the preventive measures available is a not uncommon cause of dust. Some of the men still prefer to start drilling their shotholes dry, turning on the water only when the hole has become two or three inches deep. This is done because until the hole is deep enough to contain the terminal part of the steel with its water-outlet the rapidly revolving bit throws the water back from the rock-face and the men are splashed so that their clothing gradually becomes wet. This is reputed to cause rheumatism. A type of drill which will not operate unless the water is flowing has recently been perfected.

The firing of odd shots occasionally during a shift is another cause of dust. It may happen that, coming on at the start of his shift, a man finds that his shots fired at the end of the previous shift have not fully cut out the rock as anticipated. and rather than hold up work for a whole shift he is tempted to drill a hole or two 
and blast away the rock without delay. The same temptation occurs when broken ore is found to be jammed in an ore-chute and cannot be drawn through it into the trams until a shot has been fired to free it. The more conscientious the miner the greater is his liability to offend.

The "mucker" is apt to neglect watering his pile of ore before shovelling it into the tram. This should be done repeatedly as each few shovelfuls removed expose drier material, but tin ore is heavy material to shovel, and much more so when wet. This risk will be diminished as more of the mechanical scoops described above are introduced.

It is noteworthy that while the fear of silicosis is unquestionably a real deterrent to suitable men who might enter the industry, the familiarity which the skilled miner has with dust is apt to result in carelessness. The penalty for offence, moreover, has not the immediate and dramatic quality which a breach of the regulations is apt to produce in a coal mine, and close supervision of the miners is difficult because they work in pairs in widely scattered working-places. It is desirable that education in this respect should be authoritative, imaginatively planned, and continuous through the man's working life.

\section{SILICOSIS}

There has been no comprehensive survey of silicosis in Cornwall since Haldane's "Report on the Health of Cornish Miners" in 1904, and as a detailed study is to be commenced during the present year it is proposed to limit the scope of this paper to some observations of a general nature.

Tin-miners' silicosis is of the "classical" type, that is, it consists of a generalized pulmonary fibrosis, with miliary collagenous fibrous nodulation.

Post mortem the lung is incompletely collapsed, of a greyish black colour, and the parietal surface shows numbers of sub-pleural nodules, which have a pearly pink colour (due to pleural thickening) and are surrounded by a ring of black carbon. Pleural adhesions are commonly found post mortem and are often densely fibrous; a consideration of the radiological appearances during life suggests that they are not a primary feature of the disease, but may occur later as repeated attacks of respiratory infection follow. Large emphysematous bullae are common, particularly along the anterior margin of the upper lobes. The nodules are easily palpable and of rubbery consistency, and when the lung is cut are seen to be present in great number. They are dark grey in colour, and often resemble in size and appearance the currants in a "plum-duff." The typical nodule is discrete, looking as though encapsulated, and the starfish-like processes which radiate from the coal-miner's nodule are not seen. This sharp definition of the margin of the nodule is still seen when it has grown to the "conglomerate" stage, and such masses are usually blackish rather than grey. The presence of carbon in such quantity is remarkable, for there is little smoke or carbonaceous dust in the mine atmosphere, and the men are for the most part country men. 

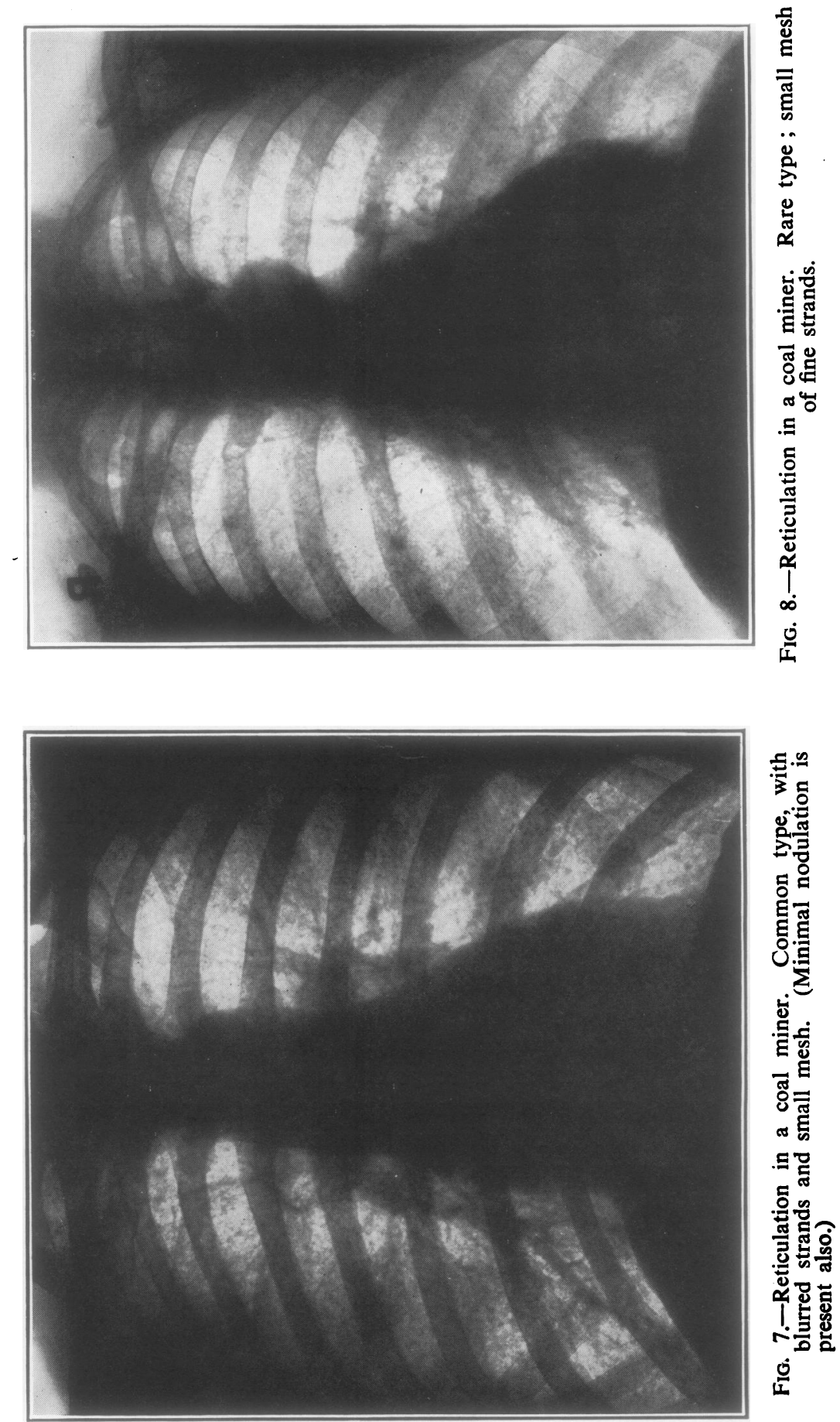
The microscopic changes include a diffuse and uniform peribronchial and interstitial fibrosis of reticular type without collagen formation, upon which are scattered the silicotic nodules. These are of the classical whorled type, the collagenous fibres forming a pattern like that of an onion when cut across; this appearance may be modified in lesions of long standing, which may show a homogeneous appearance at their centres. The tendency which the anthracotic mass has to break down at its centre is not seen. Multinucleated giant cells are a not uncommon finding in the nodules in cases showing no other evidence of tuberculosis. The glands are almost entirely converted into fibrous tissue, with much collagen, and may also show giant cells.

\section{Clinical Features}

In the Cornish mines the duration of exposure to dust before silicosis develops is stated to be from ten years upward. It is probable that the average exposure is fifteen years or more, and nodulation must be rarely seen in less than ten years, though there is general agreement, both among doctors and miners, that silicosis occurred much earlier in men who worked in the South African gold mines early in the century. It is stated that five years underground work was often found to produce the condition among these men. No cases of "acute silicosis" have been observed in this field.

The fact that, with comparable exposure, one man may be found to have no disease while another has well-marked silicosis may be due to such extraneous factors as the possession or lack of a well-shaped and well-functioning thorax, relative immunity from respiratory infections, and the existence of unsuspected pulmonary damage due to such conditions as severe whooping-cough in childhood.

The development of the disease is stated to be insidious, and this is unquestioned. A less generally appreciated fact is that the onset of symptoms is not uncommonly quite abrupt, disabling dyspnoea arising in a space of weeks without the presence of any obvious recently added infective factor. A silicotic man may be capable of light employment and yet within a week or two may die of congestive heart failure or broncho-pneumonia ; while on the other hand, miners who are being examined for other reasons are from time to time found to have advanced nodulation although they deny any respiratory symptoms. The reason for this sudden respiratory and cardiac breakdown, almost as though some threshold had been passed, is not clear, but it is noteworthy that the symptoms are by no means invariably proportional to the radiological findings.

The earliest symptom is almost invariably dyspnoea, at first present only on exertion but ultimately constant, and in the advanced case usually of asthmatic type, expiration being difficult, prolonged and wheezing. Cough, worse in the morning, with white frothy sputum, is the only other constant symptom of silicosis. Inquiry may quite often elicit an account of fleeting attacks of localized and moderate pain in the thorax, and these have been ascribed to localized pleurisy occurring over subpleural nodules; but it is usually necessary to put the leading 


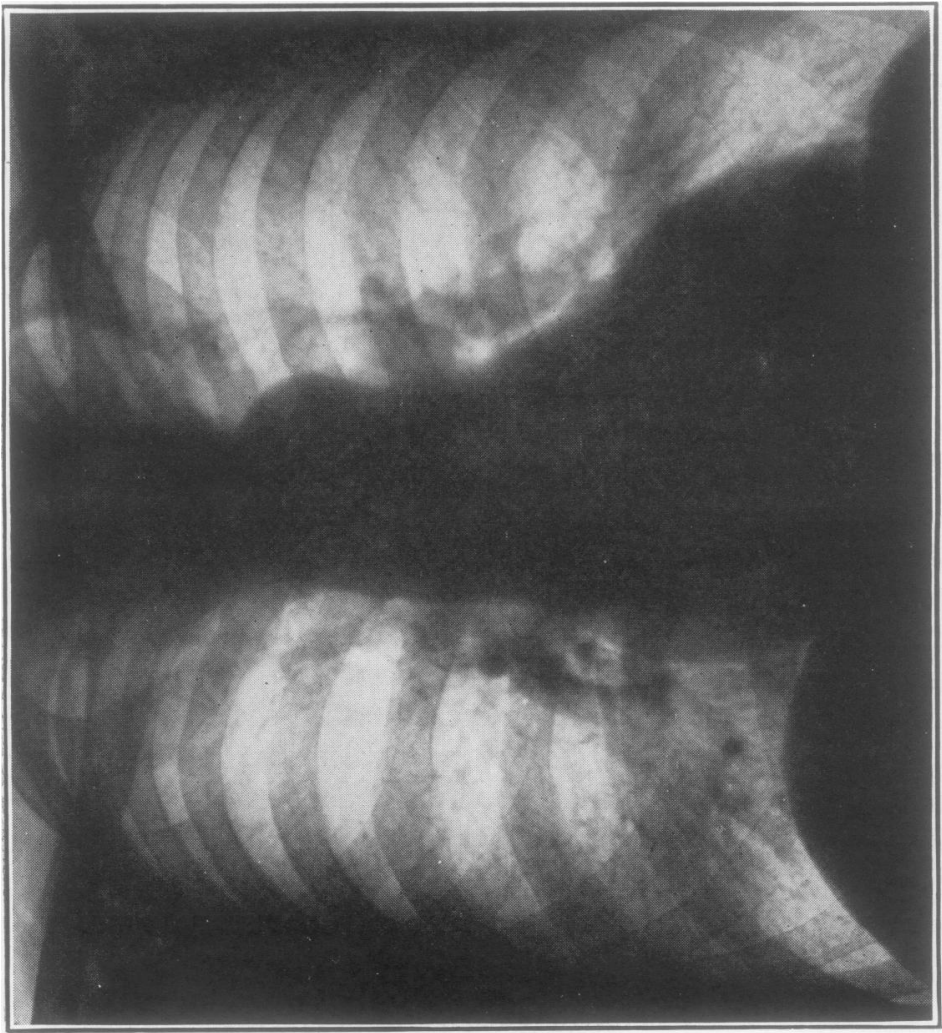

究

它

है.

폴.름

๙ 䢘它

$. \Xi:$

ธํํㅇㅎㅀ

Z

可

过

용

๙

产 
question in order to obtain this history, and in none of the cases giving it has one been able to discover objective signs of pleurisy.

While it is certain that spontaneous pneumothorax, and less often haemoptysis, occur in simple silicosis, they are more often indicative of tuberculous infection, as are loss of weight or night-sweats.

The physical signs of silicosis are those of emphysema, save that in established cases expiration is apt to be wheezing rather than of the blowing type of pure emphysema. Diminished expansion of the chest is perhaps the most significant sign, and the finding of an expansion of less than one inch (a not uncommon figure) with a symmetrically moving thorax, in a miner of middle age or less, is of near-diagnostic value.

In the absence of major infective complications the presence of nodular fibrosis may be compatible with a full expectation of life. Occasionally men in the seventh and eighth decades are found to have silicosis, and some of them have considered themselves no more breathless than their age warranted. In view of the histological changes in the lung, which must impair its vascular supply in many places in addition to causing constriction or dilatation of small bronchioles, it is difficult to imagine that such a condition as non-infective silicosis can exist ; and it may well be that the nature and degree of the secondary infection is the decisive prognostic factor. It is notable that the erythrocyte sedimentation rate is accelerated as a rule in long-standing cases and much less frequently in recent ones.

The addition of tuberculous infection has long been known to affect the prognosis drastically, and it is equally true that pulmonary tuberculosis developing in the silicotic lung is peculiarly of fibroid type with a diminished tendency to cavitation. This type of silico-tuberculosis is often obstinately sputum-negative, though typical toxic and radiological evidences of tubercle are present. Among tin-miners it has been found that when the sputum becomes positive, and still more when cavitation occurs, the patient's life expectation is to be measured in months, and healing of such cavities would seem to be rare. In Cornwall the great majority of cases at post mortem are found to have advanced tuberculosis ; in the remainder, the commonest cause of death is broncho-pneumonia or other non-tubercular respiratory infection, and a small minority die of congestive heart failure.

It has been truly said that the diagnosis of silicosis rests upon three legs: the occupational history, the radiological picture, and the physical signs; and of the three the second is so impressive as to tend to obscure the importance of the others-for cxample, one is prone to regard the degree of radiological change as an index of the degree of physical disability. The division of the radiological changes into the three major categories of reticulation, nodulation, and massive conglomeration, while convenient, is apt to infer that each case must serve its time in each category before progressing to the next, and that the disability may be expected to increase correspondingly. 

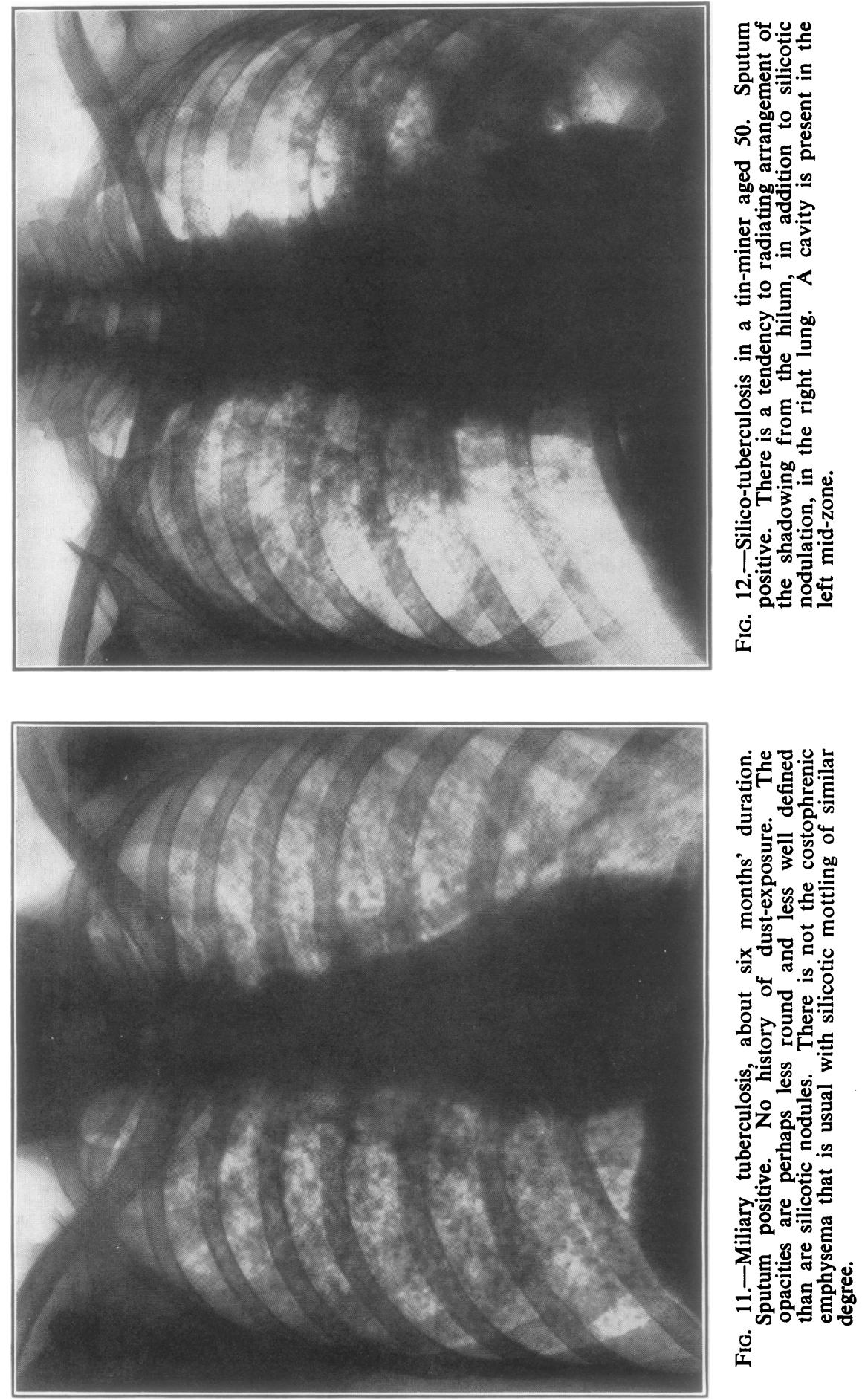
Each of these stages is represented in the x-ray picture of tin-miners' silicosis, but it would seem that there are recognizable differences between the first two stages and the corresponding-stage appearances in the pneumoconiosis of coal miners. Reticulation in the coal-miner's radiograph is a small-meshed, often rather vaguely defined network, whose strands are in many places indistinguishable from the pronounced " ground glass" background upon which they are superimposed. Hart and Aslett (1942) have described a common type in which the strands are coarse and blurred (Fig. 7), and a rare type in which the network is lacy and more clearly defined (Fig. 8). The reticulation of tin miners (Fig. 9) seems to consist of finer strands and a much wider mesh (though in the absence of standardized radiological technique it is not possible to be dogmatic), and the interstices consist of lung tissue of normal translucency. It is a much more difficult picture to differentiate from the familiar appearance of increased lungmarkings seen in mild tracheo-bronchial catarrhal infections than is that of the coal miner ; and there is much to be said for the term "arborization" which the South African writers have applied to it.

The nodulation picture (Fig. 10) is the classical one of a snowstorm of discrete rounded opacities superimposed upon reticular shadowing, and the "groundglass " background is now apparent. It is possible that in the tin miner nodulation occurs before reticulation and diffuse fibrosis have become heavy.

There is usually obvious emphysema in the lower zones, especially in the costophrenic region. It is notable that nodulation is often first detected in the right lung-field, in the upper part of the mid-zone near the hilum. The differences between the picture and that of reticulation-with-nodulation in the coal miner are a large-scale replica of those found microscopically. The tin miners' lung is more heavily peppered with nodules, which tend to be of uniform size and shape, larger and of more definite outline than the coal-miners' nodules, and without the wispy processes which the latter show. The differentiation of silicotic nodulation from miliary tuberculosis by radiology alone is so difficult as to be an academic exercise rather than a practical procedure.

The stages of "coalescent nodulation" (in which groups of nodules here and there are seen to be merging into one another) and "massive shadowing" (opacities up to the size of a five-shilling piece) are also seen in the tin miner, but differ less markedly from the corresponding stage in coal miners.

Decision upon the point at which increased lung-markings on a film cease to be within normal limits and enter the category of dust-reticulation is at present dependent upon the judgment of the individual viewing the film, and as a result any large series of films would include a considerable proportion which would be classified as showing reticulation by some workers and deemed normal by others. It may be stated that the diagnosis of reticulation is supported the more strongly as the film shows more dendritic shadows whose alignment tends to be more or less transverse to an interspace or rib - that is, that the general arrangement of the shadows should be lacework-like rather than radiating from the hilum. 

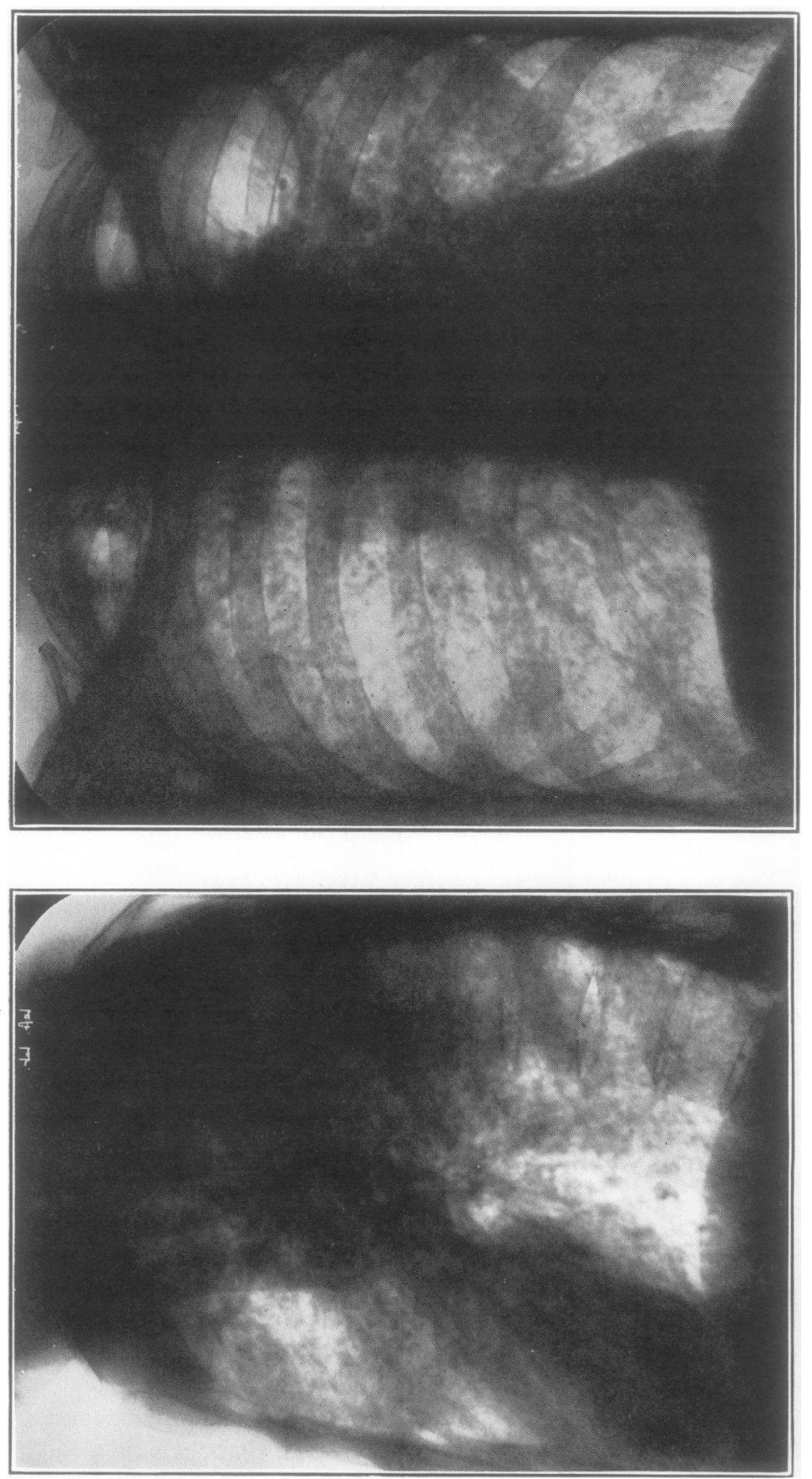
The more such a pattern is present at the periphery of the lung-fields in the mid and upper zones the more certain is the diagnosis.

Borderline pictures must inevitably exist and can be correctly classified by the taking of serial films at intervals of a year, but the correlation of the findings of different workers would be greatly assisted if a standard set of films illustrating reticulation in the pneumoconioses of various industries were prepared, agreed upon, and reproduced in full size in atlas form for comparison. An obvious difficulty in applying this method is that for films to be strictly comparable to the standard it would be necessary to standardize not only the radiographic technique used but also the type of tube.

\section{DisABILITY}

The second pressing problem calling for solution is that of evolving a method whereby pulmonary disability can be measured rather than judged. The miner is compensated for his disability and not for the amount of x-ray change in his thorax, and the function of the radiograph is to confirm that the former is in fact due to silicosis. Indeed it is possible that disability may not be proportional so much to the amount of nodulation as to the amount of diffuse parenchymatous fibrosis in the lung.

It must be admitted that the tests which have at present been applied for this purpose are either liable to be inaccurate or are too difficult for routine use. The exertion tolerance test, which has perforce to be the mainstay in disability assessment, may be invalidated by cardiovascular considerations, and is moreover objectionable on the score that an elderly miner, becoming arthritic, may find it difficult to mount and dismount from a chair at the standard rate. A man who is acutely anxious as to whether he has silicosis may be dyspnoeic during (or indeed before) the test. The technique of spirometry is not easy to explain to the working man, and while it is doubtless capable of indicating unequivocally the presence of gross pulmonary disability, it is less certain in view of the wide individual variations in vital capacity, etc., that it would reveal the effect of earlier changes. It is however possible that serial spirometric records of workers would be of real value. Determination, by estimation of the arterial-blood-oxygen, of the capacity of the lungs to oxygenate the blood would seem to be the ideal method, but is at present too difficult to apply to large numbers of men.

It is not doubted that in the majority of cases a careful consideration of the clinical findings, together with an exertion tolerance test, will enable an experienced worker to estimate disability fairly accurately, but he may find it difficult to sustain his opinion in discussion. The problem is complicated by the fact that the silicotic man's respiratory efficiency may vary considerably from week to week under such influences as those of trivial respiratory infections or changes of weather. A man who shows doubtful disability on a fine warm day may have obvious dyspnoea at rest if he has had to travel through cold wet weather for examination. This fact, involving as a result the liability of a partially disabled 
silicotic to frequent absences from work in any employment for which he may be considered suitable is one which should be taken into account in any plan for grading or rehabilitating the silicotic miner.

\section{SUMMARY}

1. Geological and chemical conditions relative to the deposition of tin-ore are outlined.

2. The practice of tin mining in Cornwall is described, and reference is made to rock-drills and drilling methods.

3. Environmental considerations discussed include references to country-rock, naturally occurring water, thermal conditions, and the occurrence of dust.

4. Dust-prevention methods in use at present are indicated and difficulties of application mentioned.

5. Some observations on the clinical, pathological, and x-ray features of silicosis as it occurs among Cornish tin miners are given, and difficulties in the interpretation of radiographs and assessment of respiratory disabilty are discussed.

\section{REFERENCES}

Haldane, J. S., Martin, J. S., and Thomas, R. A. Report on the Health of Cornish Miners, H.M. Stationery Office, 1904.

Hart, P. d'A., Aslett, E. A., and Belt, T. (1942). M.R.C. Spec. Rept., Series No. 243.

It is a pleasure to acknowledge the help of Messrs. H. Bennetts, C. V. Paull, G. Sims, and the staffs of Geevor and South Crofty Tin-mines; Dr. E. T. Gaspey and Mr. Dilwyn Thomas, for loan of films ; A. Treve Holman, Esq., for advice on mining machinery ; and G. A. Whitworth, Esq., Camborne School of Metalliferous Mining, for reading and making suggestions in the preparation of this paper. 